Supplement of Hydrol. Earth Syst. Sci., 23, 393-403, 2019

https://doi.org/10.5194/hess-23-393-2019-supplement

(c) Author(s) 2019. This work is distributed under

the Creative Commons Attribution 4.0 License.

(c) (1)
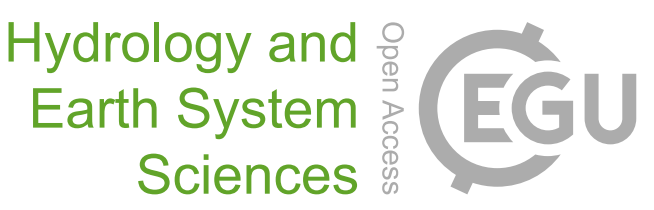

Supplement of

\title{
Flooded by jargon: how the interpretation of water-related terms differs between hydrology experts and the general audience
}

Gemma J. Venhuizen et al.

Correspondence to: Rolf Hut (r.w.hut@tudelft.nl)

The copyright of individual parts of the supplement might differ from the CC BY 4.0 License. 


\section{Questionnaire hydrological terms}

Thank you for participating in this survey! We will ask you some questions about water and terminology. We are not looking for a 'right' answer, but for the answer that is, in your opinion, the best definition.

It will take approx. 5 minutes to participate. Have fun!

1. What is, in your opinion, the best definition of a river?

A: Path of fresh water flowing into the ocean

B: Water flowing only on the surface of the land and never underground

C: Large stream which serves as the natural drainage for a basin

D: Flow of surface water within a straight channel

2. What is, in your opinion, the best definition of a river basin?

A: Area having a common outlet for its surface runoff

B: Dry river channel which may be flooded during high water events

c: Catchment which a river flows into

D: Body of water (lake, sea, ocean) a river flows into

3. What is, in your opinion, the best definition of groundwater?

A: All water stored in the ground

B: All water which is in direct contact with the ground

C: Water flowing under ground

D: Subsurface water occupying the saturated zone

4. What is, in your opinion, the best definition of an aquifer?

A: Subsurface water body

B: Groundwater that reaches the surface through a permeable rock layer

C: Geological formation capable of storing, transmitting and yielding water

D: Man-made structure first built by the Romans to transport water

5. What is, in your opinion, the best definition of a lake?

A: Man-made body of standing surface water of significant extent

B: Inland body of standing surface water of significant extent

C: Small body of water encompassed by high mountains

D: Area of variable size filled with water 
6. What is, in your opinion, the best definition of a dam?

A: Barrier constructed across a valley to store water or raise the water level

B: Barrier that prevents a river to flow into a lake

C: Man-made, giant concrete structure to regulate water flow

D: Man-made object to keep rivers or seas from overflowing land

7. What is, in your opinion, the best definition of a delta?

A: Feature resulting from an alluvial deposit at a rivermouth

B: River mouth that spreads out a little bit, like the shape of a Greek letter Delta

C: Triangular shaped island in a river

D: Landform that forms from deposition of sediment carried by a river

8. What is, in your opinion, the best definition of downstream?

A: Heavy intensity rain water falling down

B: Direction from which a fluid is moving

C: Stream that branches off from the main stream

D: Direction in which a fluid is moving

9. What is, in your opinion, the best definition of a flood?

A: Large wave of moving water

B: Overflow of water onto lands that are not normally covered by water

C: Rise in the water level to a peak from which it recedes at a slower rate

D: Unusually large run-off event that leads to economic damage

10. What is, in your opinion, the best definition of a stream?

A: River that drains into another river and not into a lake, sea or ocean

B: Watercourse that flows into a larger watercourse or into a lake

C: Small river with water moving fast enough to be visible with the naked eye

D: General term for any body of flowing water 
11. What is, in your opinion, the best definition of discharge?

A: Volume of water that passes through the whole river in one day

B: Volume of water flowing through a river cross-section per unit time

C: Water with enough sediment in it to limit visibillity to less than 1 feet

D: Flowing water in a reservoir used to generate electricity

12. What is, in your opinion, the best definition of a water table?

A: Top surface of the zone of saturation

B: Saturated part of an aquifer

C: Tide table kept at water authority

D: Height to which water raises in a well

13. Which of the following photos is, in your opinion, the best depiction of a geyser?

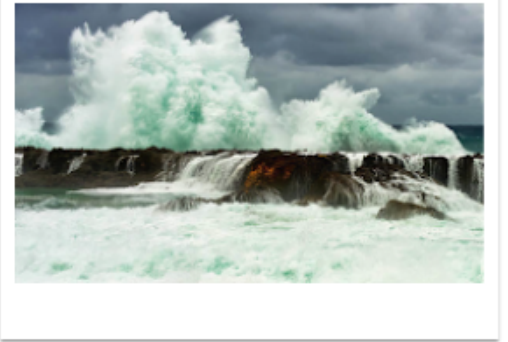

A:

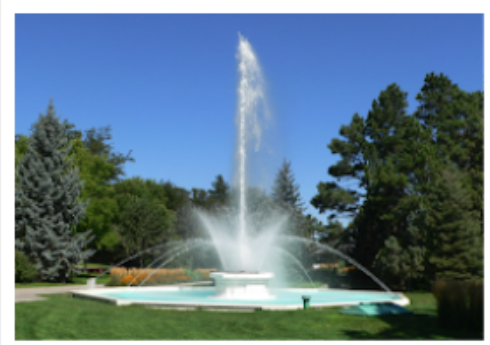

C:

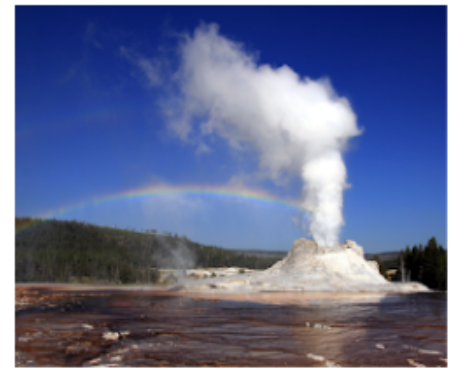

B:

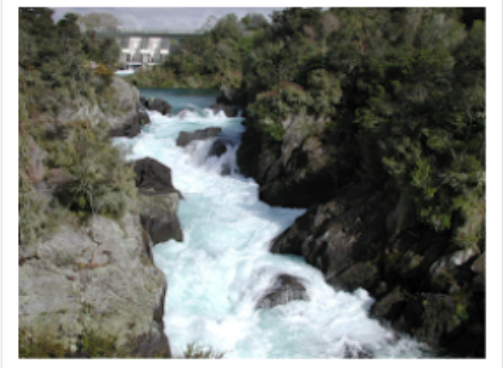

D: 
14. Which of the following photos is, in your opinion, the best depiction of a sewer?

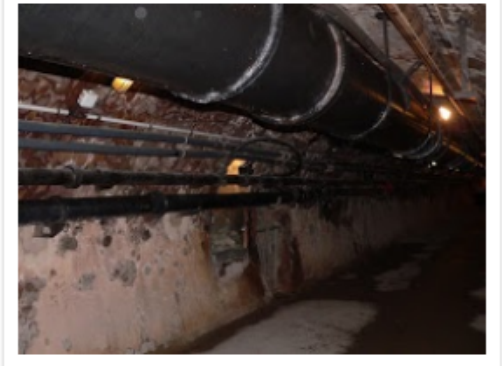

A:

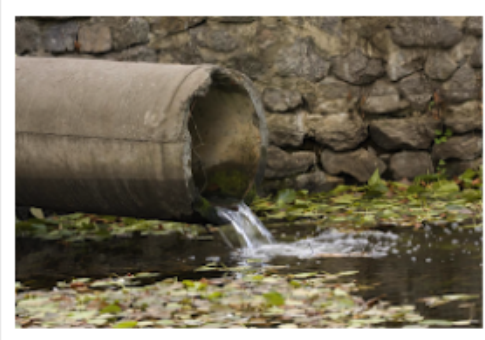

C:

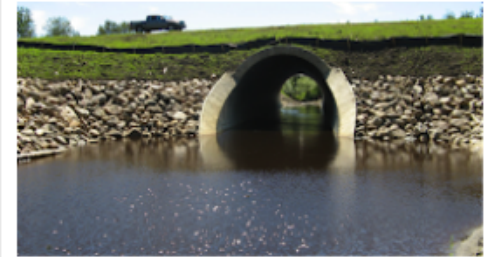

B:

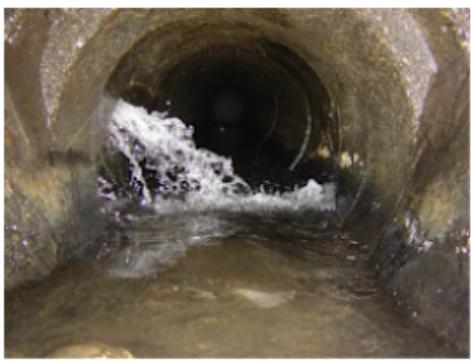

D:

15. Which of the following photos is, in your opinion, the best depiction of a flood?

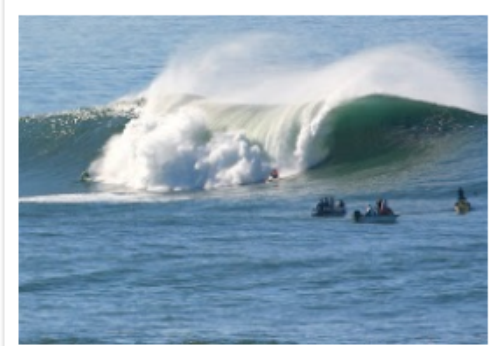

A:

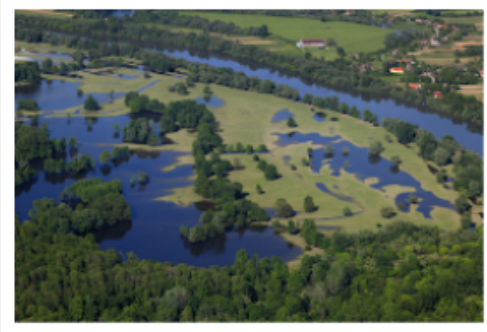

C:

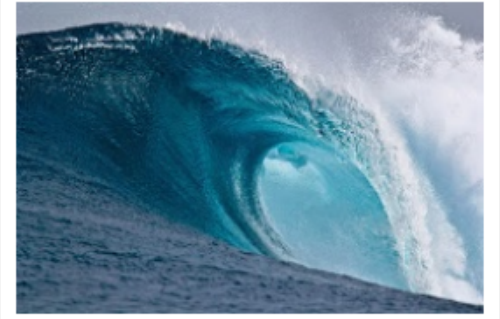

B:

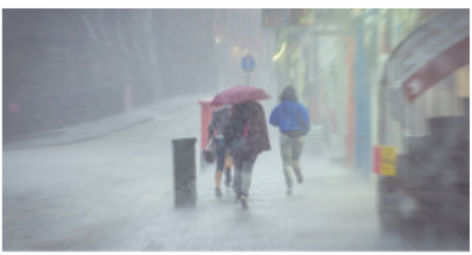

D: 
16. Which of the following photos is, in your opinion, the best depiction of a pond?

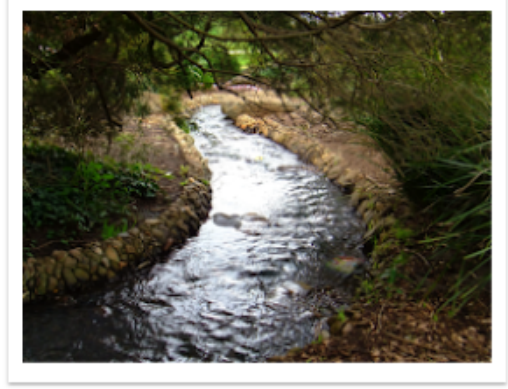

A:

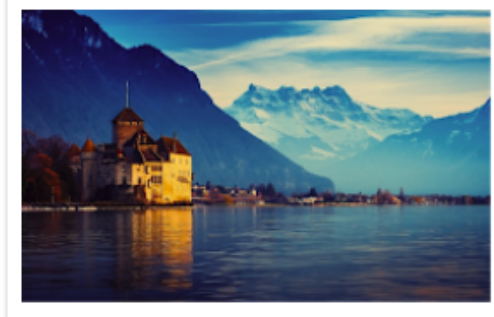

C:

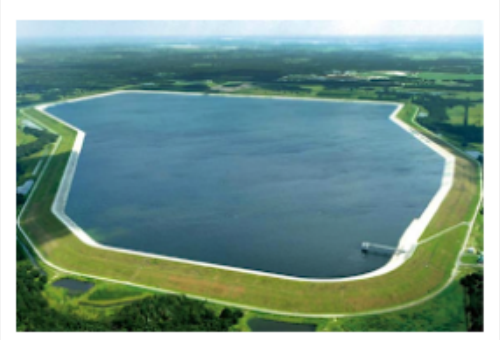

B:

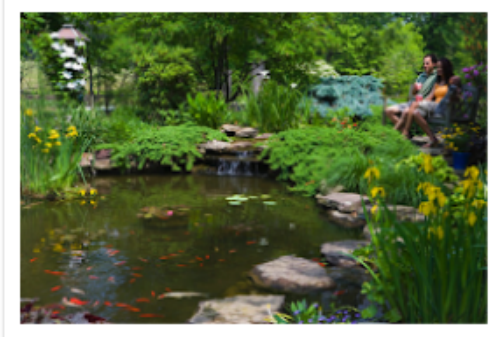

D:

17. Which of the following photos is, in your opinion, the best depiction of a swamp?

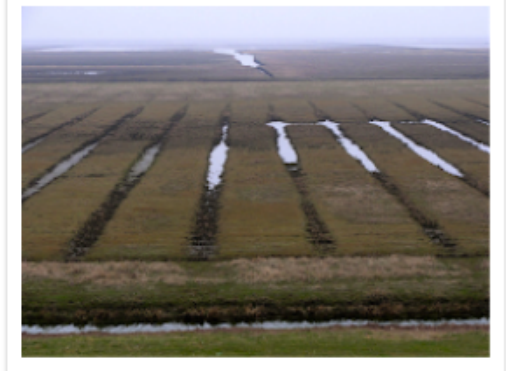

A:

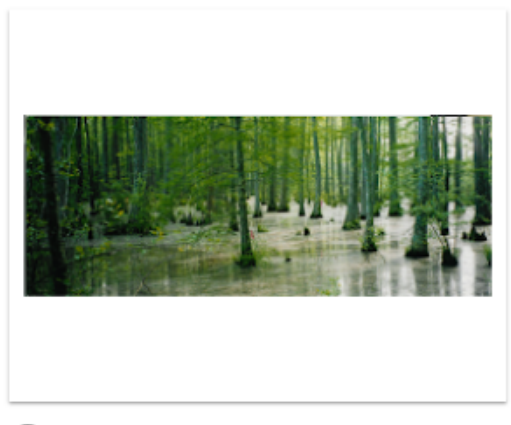

c:

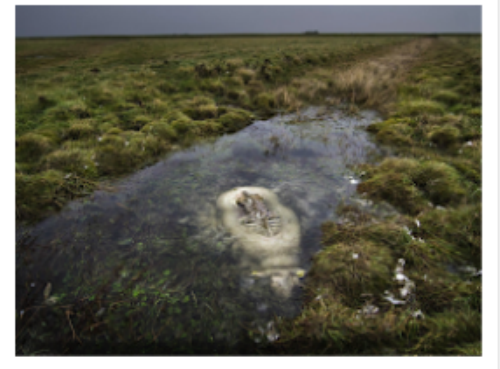

B:

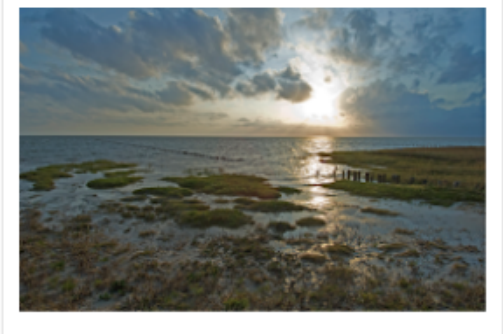

D: 
18. Which of the following photos is, in your opinion, the best depiction of hydro power?

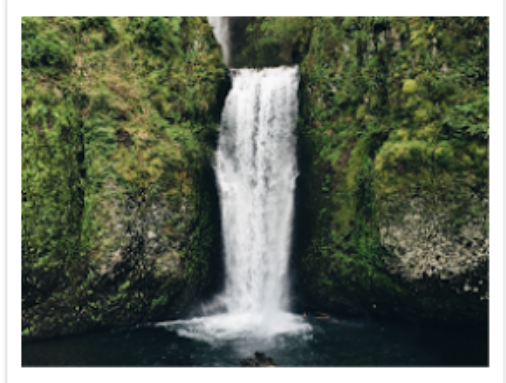

A:

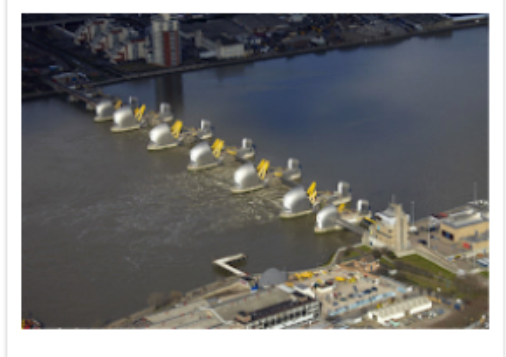

C:

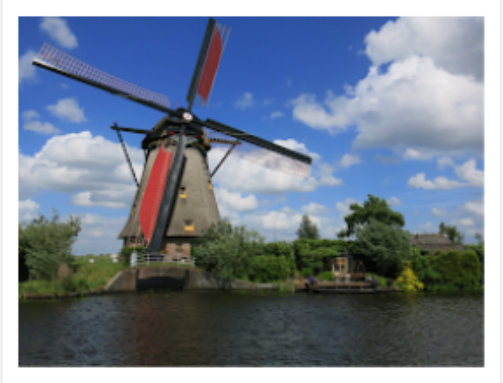

B:

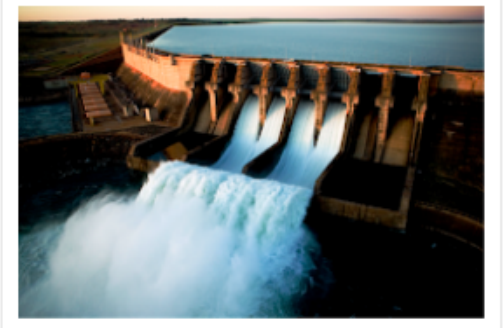

D:

19. Which of the following photos is, in your opinion, the best depiction of a reservoir?

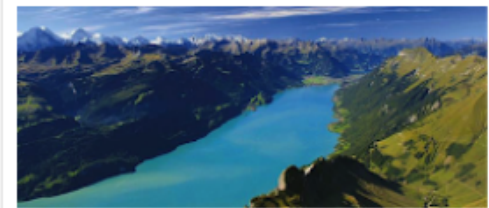

A:

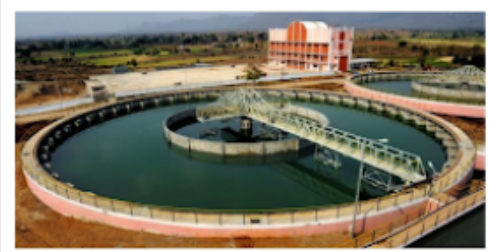

C:

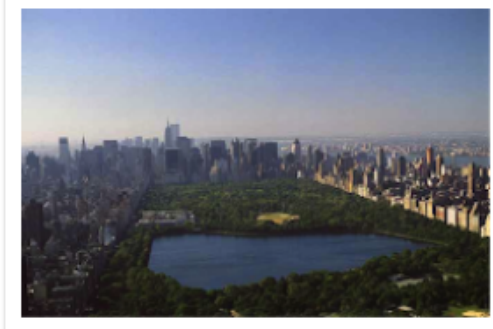

B:

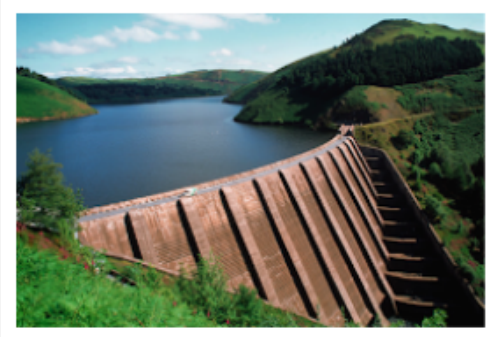

D: 
20. Which of the following photos is, in your opinion, the best depiction of a dike?

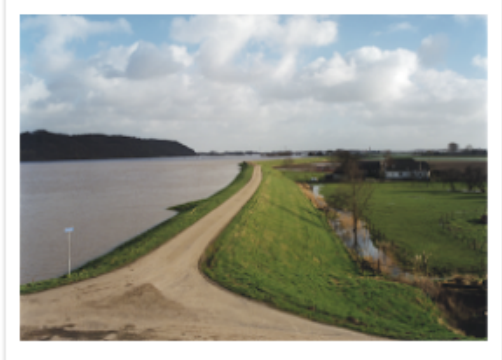

A:

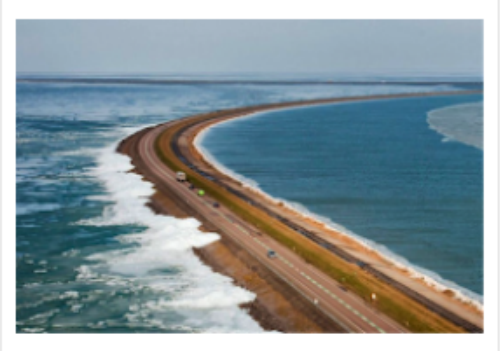

C:

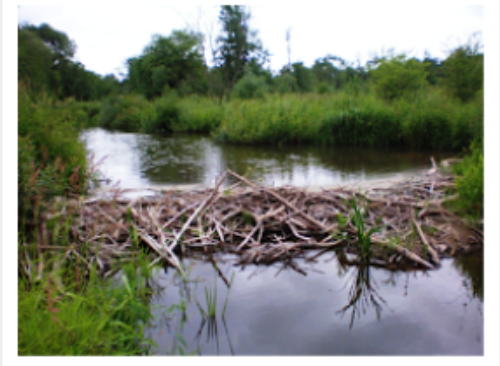

B:

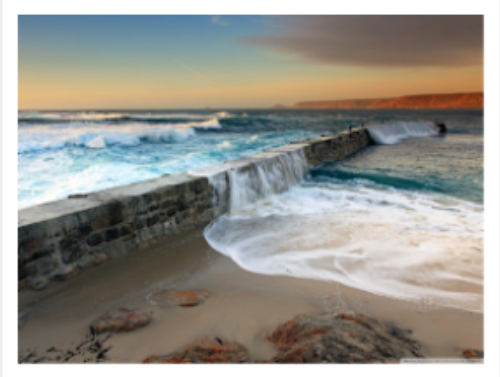

D:

21. Which of the following photos is, in your opinion, the best depiction of a river?

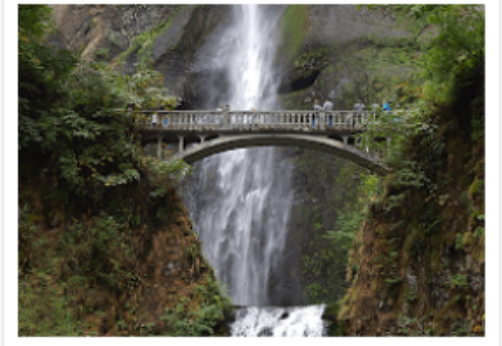

A:

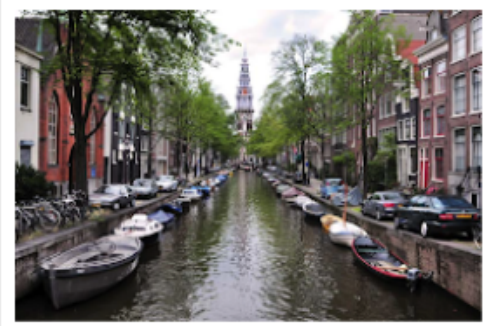

C:

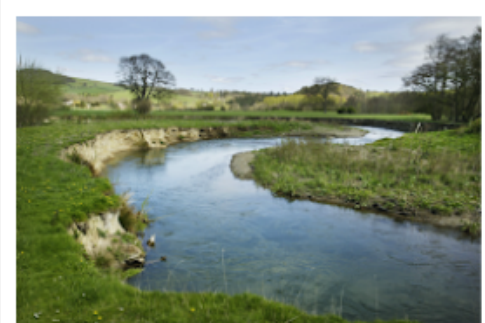

B:

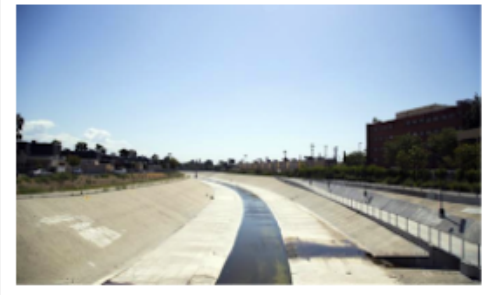

D: 
22. Which of the following photos is, in your opinion, the best depiction of dew?

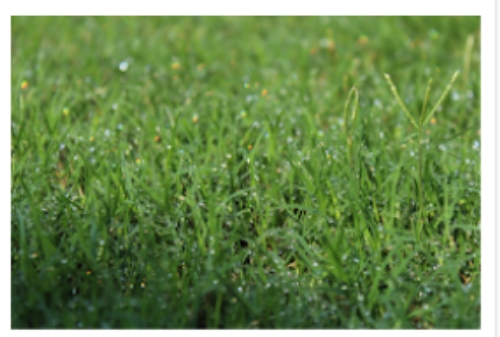

A:

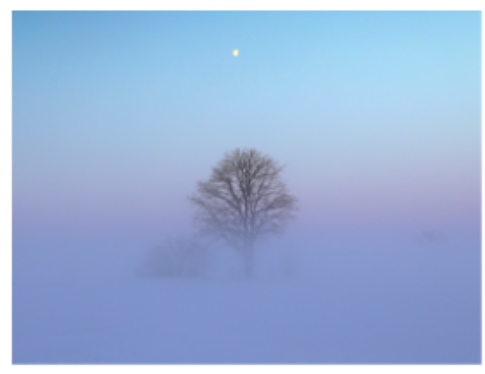

C:

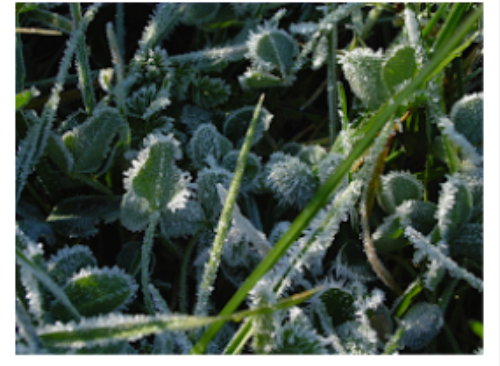

B:

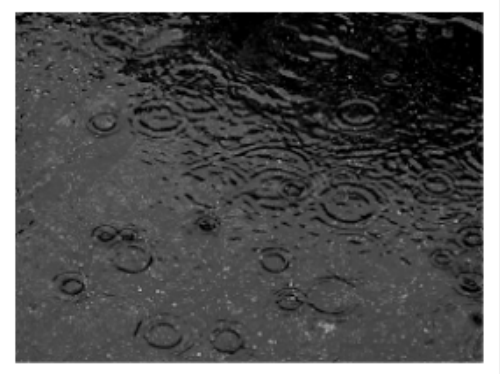

D:

23. Do you have any comments concerning the questions?

Your answer

24. What is your gender?

Female

Male

Other or prefer not to say

25. What is your age?

Your answer

26. What is your country and postcode area?

Your answer

27. What is your highest completed education level? 